\title{
Características da camada-limite convectiva durante a transição da estação seca para chuvosa na Amazônia: comparação floresta/pastagem
}

Com o objetivo de investigar o comportamento termodinâmico da camada limite convectiva (CLC) na transição da estação seca para a chuvosa 2002/2003 no Oeste da Amazônia (Rondônia), foram comparados resultados observacionais obtidos em dois tipos de cobertura vegetal: floresta nativa e pastagem plantada. Os dados foram obtidos durante a campanha de 2002 do LBA (DRY TO WET) no período de 16 de setembro a 31 de outubro. Os resultados mostraram que o padrão de evolução da CLC, tanto na floreta, quanto na pastagem, foi bastante parecido com aqueles observados na estação chuvosa (LBA 1999). Em termos de desenvolvimento vertical, tanto os padrões de crescimento como os valores de espessura alcançados nos dois sítios foram praticamente iguais. A média na floresta foi de $858 \mathrm{~m}$ e na pastagem de $888 \mathrm{~m}$. Os padrões de evolução dos valores médios e das taxas de variação temporal nos dois sítios, no interior da CLC, são, na sua maioria, semelhantes.

Palavras-chave: Camada-limite Convectiva; Amazônia; Desmatamento.

\section{Characteristics of the convective boundary layer during the transition from dry to rainy season in Amazonia: forest/pasture comparison}

In order to investigate the thermodynamic behavior of the convective boundary layer (CLC) in the transition from the dry season to the rainy season 2002/2003 in western Amazonia (Rondônia), we compared the observational results obtained in two types of vegetation cover: native forest and pasture planted. Data were obtained during the 2002 LBA (DRY TO WET) campaign from September 16 to October 31. The results showed that the evolution pattern of CLC, both in the floret and in the pasture, was very similar to those observed in the rainy season (LBA 1999). In terms of vertical development, both growth patterns and thickness values at both sites were practically the same. The mean in the forest was $858 \mathrm{~m}$ and the pasture was $888 \mathrm{~m}$. The patterns of evolution of the mean values and temporal variation rates at the two sites within the CLC are, for the most part, similar.

Keywords: Convective Boundary Layer; Amazonian; Deforestation.

Topic: Uso de Recursos Naturais

Reviewed anonymously in the process of blind peer.

Christiane Cavalcante Leite

Instituto Federal de Alagoas, Brasil

http://lattes.cnpq.br/3119997635801028

http://orcid.org/0000-0002-4218-6654

ccleite@gmail.com

Roberto Fernando da Fonseca Lyra

Universidade Federal de Alagoas, Brasil

http://lattes.cnpq.br/4402659341854500

roberto.ufal@gmail.com

Ranieri Carlos Ferreira de Amorim (iD)

Centro Universitário Maurício de Nassau, Brasil

http://lattes.cnpq.br/6639209700174709

http://orcid.org/0000-0001-8056-7661

rcfamorim@gmail.com
Received: 19/08/2017

Approved: 18/11/2017
Referencing this:

LEITE, C. C.; LYRA, R. F. F.; AMORIM, R. C. F.. Características da camada-limite convectiva durante a transição da estação seca para chuvosa na Amazônia: comparação floresta/pastagem. Nature and Conservation, v.10, n.2, p.6-14, 2017. DOI: http://doi.org/10.6008/SPC2318-2881.2017.002.0001 


\section{INTRODUÇÃO}

Com uma área de cerca de $7.500 .000 \mathrm{Km}^{2}$, a Floresta Amazônica vem sendo degradada desde a ocupação dos exploradores europeus no século XVI. Estima-se que uma área de aproximadamente $16 \%$ da floresta original, já tenha sido desmatada através da derrubada e da queima da biomassa (MOLION, 1995). Mudanças na cobertura do solo provoca alterações nos parâmetros locais como albedo e rugosidade os quais afetam o balanço de energia local que, por sua vez, interage modifica, a Camada Limite Atmosférica (CLA).

A CLA é a região onde ocorre a maioria dos transportes de energia (calor sensível e latente) no sistema Terra - Atmosfera. Durante o dia ela sofre forte influência da convecção e por isso é chamada de camada limite convectiva (CLC). As diferenças existentes no tipo de superfície e rugosidade do terreno contribuem diretamente para a maneira como a CLA influencia este transporte de energia (FINIGAN et al., 1994; STULL, 1988). Experimentos em regiões de floresta e de pastagem (área desmatada) na Amazônia vêm sendo realizados desde 1983 com o objetivo de estudar o efeito do desmatamento nos processos de interação floresta-atmosfera no que diz respeito a CLA, bem como estabelecer os processos físicos, biológicos e fisiológicos que interagem com a atmosfera e causam alteração no clima (COHEN et al., 2000).

Dentre os vários experimentos de campo que já foram realizados na região Amazônica, destaca-se o projeto LBA "Large Scale Biosphere-Atmosphere in Amazonia", no qual foram realizadas duas campanhas. A primeira, denominada WET, ocorreu durante a estação chuvosa de 1999. A segunda denominada DRY TO WET teve lugar durante o período de setembro a novembro de 2002, na transição da estação seca para a chuvosa.

Comparações na evolução da CLA durante a estação chuvosa (LBA - 1999) e a estação seca (RBLE 3), em área de pastagem e floresta no oeste da Amazônia foram discutidas por Rocha et al. (2002). Os resultados mostraram significantes diferenças entre as duas estações, tanto na CLC quanto na Camada limite Estável (CLE). Lyra et al. (2003), utilizaram dados dos projetos RBLE (estação seca) e LBA - 1999 (estação chuvosa) para comparar os principais aspectos termodinâmicos da CLC na floresta e na pastagem entre as duas estações. Os resultados mostraram que na estação seca a CLC na região desmatada é substancialmente diferente daquela que se desenvolvi sobre a floresta. O principal objetivo deste trabalho é comparar o comportamento da CLC sobre as áreas de floresta e pastagem durante a estação de transição na Amazônia, e comparar o desenvolvimento da mesma em outros períodos (seco e chuvoso).

\section{MATERIAIS E MÉTODOS}

Os dados utilizados foram colhidos durante a campanha do projeto DRY TO WET-AMC/LBA, nos meses de setembro e outubro de 2002, na região Sul de Rondônia, em dois sítios experimentais: uma área de floresta nativa (Reserva Biológica do Jaru (Ji-Paraná), $10^{\circ} 05^{\prime} \mathrm{S}, 61^{\circ} 55 \mathrm{~W}, 120 \mathrm{~m}$ ) e outra desmatada utilizada como pastagem (Fazenda Nossa Senhora (Ouro Preto do Oeste), $10^{\circ} 45^{\prime} \mathrm{S}, 62^{\circ} 22^{\prime} \mathrm{W}, 293 \mathrm{~m}$ ).

Foram utilizados também perfis verticais de pressão atmosférica, temperatura do ar, umidade e vento, medidos com radiossondas nos seguintes horários: 08h, 11h, 14h e 17h (hora local). Apesar da 
intenção de realizar sondagens simultâneas em algumas ocasiões isto não foi possível. Na pastagem foram obtidos dados no período de 12 de setembro a 31 de outubro e na floresta a coleta foi de 11 a 29 de setembro e de 15 a 30 de outubro. A partir dos dados de pressão, umidade, temperatura, velocidade e direção do vento foram calculadas todas as variáveis necessárias: Temperatura Potencial Virtual $\left(\theta_{v}\right)$, Umidade Especifica (q), Componentes Zonal e Meridional do Vento ( $u$ e v) e Razão de Mistura ( $r$ ) bem como seus gradientes médios e as taxas de variação, conforme proposto no Quadro 1. Em seguida, foi feita uma interpolação linear (1 ponto a cada $25 \mathrm{~m}$ ) para facilitar a plotagem dos gráficos dos perfis de $\theta_{\mathrm{v}}$.

Quadro 1: Lista de variáveis calculadas a partir dos dados de radiossonda

\begin{tabular}{|ccc|}
\hline Variável & Símbolo & Equação \\
Temperatura potencial virtual & $\theta_{\mathrm{v}}$ & $\theta_{V}=\theta(1+0,61 r)$ \\
Umidade especifica & $\mathrm{q}$ & $q=0,622 \frac{e}{P-0,378 e}$ \\
Razão de mistura & $\mathrm{r}$ & $r=0,622 \frac{e}{P-e}$ \\
Componente zonal do vento & $\mathrm{u}$ & $\mathrm{u}=$-ffsen(dd) \\
Componente meridional do vento & $\mathrm{v}$ & $\mathrm{v}=\mathrm{ffcos}(\mathrm{dd})$ \\
Gradientes médios & $\bar{X}$ & $\bar{X}=\frac{\sum_{Z_{s}} \frac{\partial X}{\partial Z}}{n}=\sum_{Z_{s}}^{Z_{I}} \frac{\Delta X}{\Delta Z}=\sum_{Z_{s}} \frac{Z_{Z_{2}}}{Z_{2}-X_{1}}$ \\
Taxa de variação & $\frac{\partial x}{\partial_{t}}$ & $\frac{\partial x}{\partial t}=\frac{x_{T 2}-x_{T 1}}{t_{2}-t_{1}}$ \\
\hline
\end{tabular}

Uma vez que o objetivo do trabalho é comparar o comportamento da CLC sobre os dois tipos de cobertura do solo (floresta e pastagem) foram selecionados, para análise, apenas os dias em que houve sondagens simultâneas nos quatro horários nos dois sítios (18, 24, 27 e 29 de setembro e 15, 16 e 17 de outubro). Para determinar a altura da CLC (Zi), foi utilizado o modelo analítico clássico proposto por Stull, (1988) onde Zi é definido pela base da inversão térmica conforme ilustrado na figura 1.

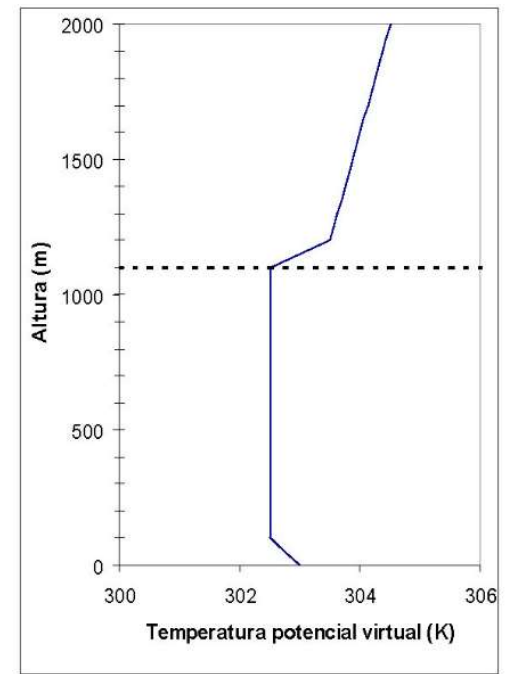

Figura 1: Ilustração do modelo analítico para obtenção da altura da CLC (Zi). A linha pontilhada indica a altura da CLC. 


\section{RESULTADOS E DISCUSSÃO}

Quando comparamos os valores médios de temperatura potencial virtual $\left(\theta_{v}\right)$ e umidade especifica (q), bem como seus respectivos gradientes no interior da CLC, de acordo com o apresentado na figura 2a, verificamos comportamentos similares nos dois sítios em alguns horários. A temperatura potencial, ainda nos referindo à figura $2 \mathrm{a}$, é sempre maior na pastagem, mas à medida que o tempo passa a diferença vai diminuindo e no final ela é praticamente nula. A média geral na floresta foi 305,30K e na pastagem 306,15K. Com relação ao gradiente de $\theta_{\mathrm{v}}$, em consonância à figura $2 \mathrm{~b}$, no interior da $\mathrm{CLC}$, tanto na floresta quanto na pastagem ele foi ligeiramente negativo. Com exceção das $08 \mathrm{H}$ o padrão de evolução nos dois sítios foi idêntico. $\mathrm{O}$ gradiente mais forte as $08 \mathrm{H}$ na pastagem certamente está ligado ao aquecimento mais rápido da superfície por conta da ausência de vegetação. Na média geral o gradiente foi maior na pastagem ($0,0015 K \cdot \mathrm{m}^{-1}$ contra $\left.-0,0026 \mathrm{~K} \cdot \mathrm{m}^{-1}\right)$.

A umidade específica média, de acordo com o exposto na figura $2 \mathrm{~b}$, de uma maneira geral, diminui ao longo do dia sendo que, na pastagem verifica-se um aumento as $11 \mathrm{H}$. Isto já foi verificada em estudos anteriores (SOUSA, 1997; ROCHA, 2003) e, segundo os autores, seria resultado do transporte horizontal de umidade da floresta para a pastagem. É importante salientar que o vento predominante sopra no sentido floresta-pastagem. A média geral na pastagem foi $14,51 \mathrm{~g} \cdot \mathrm{kg}^{-1}$ e na floresta $14,63 \mathrm{~g} \cdot \mathrm{kg}^{-1}$. Com relação ao gradiente médio de umidade (Figura $2 \mathrm{~d}$ ), observa-se um comportamento bastante semelhante ao da temperatura (Figura $2 \mathrm{c}$ ). A media geral na floresta foi $-0,008 \mathrm{~g} \cdot \mathrm{kg}^{-1} \cdot \mathrm{m}^{-1}$ e na pastagem $-0,006 \mathrm{~g} \cdot \mathrm{kg}^{-1} \cdot \mathrm{m}^{-1}$.

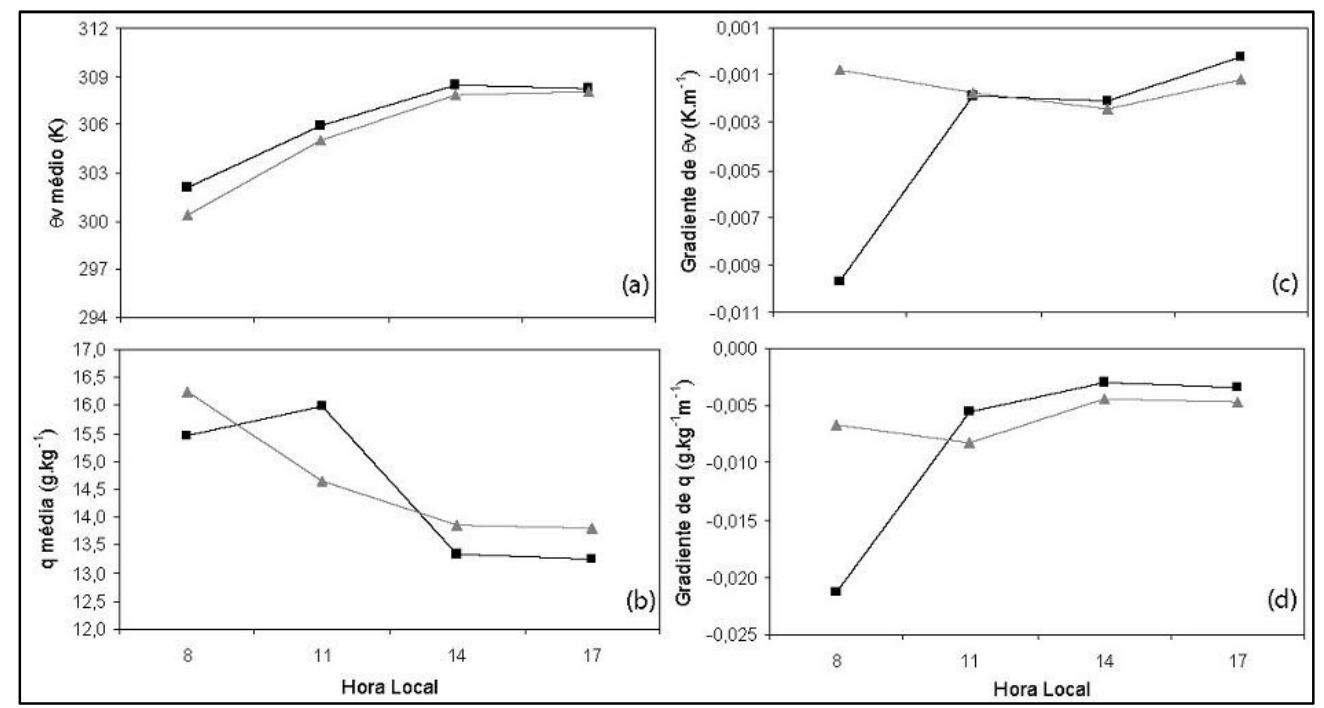

Figura 2: Médias horárias da Temperatura potencial virtual (a), umidade especifica (b), gradiente de $\theta \mathrm{v}$ (c) e gradiente de q (d) na floresta ( $\Delta$ ) e na pastagem ( $\mathbf{a}$ ) para os dias 18, 24, 27 e 29 de setembro e 15, 16 e 17 de outubro de 2002.

Na figura 3 há uma comparação entre os perfis médios de $\theta_{v}$ na floresta e na pastagem nos quatro horários de sondagem $(08,11,14$ e $17 \mathrm{H})$. Verificamos que, de uma maneira geral, a forma dos perfis nos dois sítios é praticamente a mesma. Por outro lado, a temperatura é quase sempre superior na pastagem. No inicio do dia $(08 \mathrm{H})$, quando o sol está começando a aquecer a superfície, a altura da CLC é ainda muito pequena e difícil de ser identificada com os dados fornecidos pela radiossonda, conforme a figura 3a. No entanto, é possível verificar que ela está surgindo por baixo da camada estável (resto da CLN) próximo a 
superfície. O fato de a inversão noturna permanecer até a metade da manhã já é bastante conhecido. Segundo Fisch et al. (1996) a quebra de inversão noturna ocorre somente a partir das 09H. Nos primeiros 750m há uma diferença média de 1,30K a favor da pastagem. A partir dessa altura os perfis são praticamente iguais.

No horário seguinte $(11 \mathrm{H})$ a CLC na pastagem se mostra mais quente e bem mais misturada do que na floresta. Na floresta há ainda traços da inversão noturna e o perfil na CLC apresenta um gradiente estaticamente estável, como se pode notar na ilustração da figura 3b. Acima da CLC não existem diferenças significativas, mas em duas ocasiões $(1000 \mathrm{~m}$ a $1600 \mathrm{~m}$ e $2500 \mathrm{~m}$ a $3300 \mathrm{~m})$, a pastagem apresenta temperatura ligeiramente superior. $\mathrm{O}$ fato mais marcante verificado às $14 \mathrm{H}$ é que o ar está nitidamente mais quente na pastagem tanto na CLC como acima dela (Figura 3c). As diferenças (pequenas) nos gradientes de energia à superfície não são suficientes para explicar o aquecimento acima da CLC. Este ponto será abordado mais adiante durante a análise das taxas de aquecimento/resfriamento. No final da tarde $(17 \mathrm{H})$ os perfis são praticamente idênticos nos dois sítios sendo que a temperatura é ligeiramente superior na pastagem e a diferença de temperatura cresce com a altura (Figura 3d). Percebe-se também o inicio da formação da camada noturna em ambos os sítios fato voltará a ser abordado mais adiante.

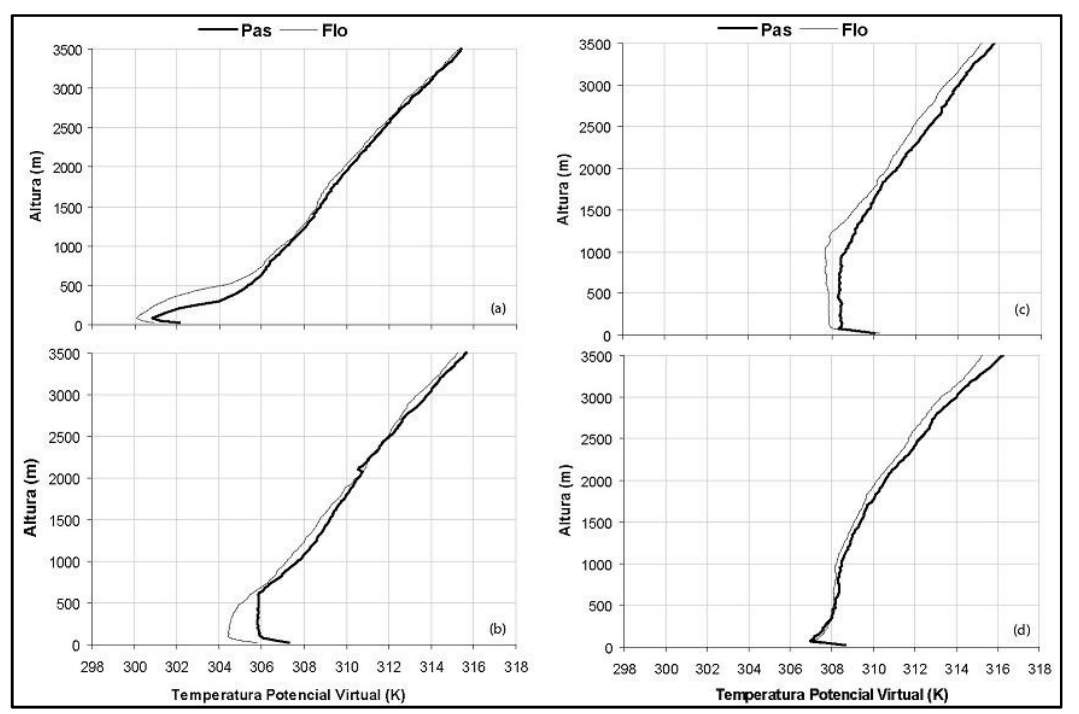

Figura 3: Perfil vertical médio da Temperatura Potencial Virtual (K) na floresta (FLO) e pastagem (PAS) às $08 \mathrm{H}(\mathrm{a}), 11 \mathrm{H}$ (b), $14 \mathrm{H}(\mathrm{c})$ e $17 \mathrm{H}(\mathrm{d})$.

Na tentativa de compreender melhor o fato de haver aquecimento significativo acima da CLC, serão analisados a seguir os perfis médios da taxa de aquecimento/resfriamento ( $\partial \theta / \partial t)$. Na Figura 4 são mostrados os perfis médios de " $\partial \theta / \partial \mathrm{t}$ " nos dois sítios nos intervalos entre $08 \mathrm{H}-11 \mathrm{H}, 11 \mathrm{H}-14 \mathrm{H}$ e $14 \mathrm{H}-17 \mathrm{H}$. Nela fica evidente a existência de um forte aquecimento próximo à superfície, explicitado na figura 4a, que diminui com a altura e tende a zero próximo dos $600 \mathrm{~m}$. Esta camada representa espessura aproximada da CLC nos dois sítios às $11 \mathrm{H}$. Acima desta altura existe um ligeiro aquecimento que varia entre 0 e $0,25 \mathrm{~K}$ sendo um pouco mais pronunciado na pastagem.

No intervalo entre $11 \mathrm{H}$ e $14 \mathrm{H}$ (Figura 4b), com exceção dos primeiros $500 \mathrm{~m}$, já se observa um maior aquecimento na pastagem,. Como observado no período anterior ( 8 a $11 \mathrm{H})$, o aquecimento é maior no 
interior CLC (1150m às 14H) e ocorre uma importante diminuição com a altura (da superfície até o topo da CLC). A partir daí, o aquecimento na floresta é muito pequeno chegando até a resfriar um pouco acima de $3250 \mathrm{~m}$. Na pastagem observa-se um aquecimento mais efetivo, principalmente entre $2200 \mathrm{~m}$ e $2700 \mathrm{~m}$.

No intervalo das $14 \mathrm{H}$ às $17 \mathrm{H}$ observamos um resfriamento na pastagem da superfície até cerca de $3200 \mathrm{~m}$. Já na floresta ocorre aquecimento entre $300 \mathrm{~m}$ e $1220 \mathrm{~m}$ e entre $3200 \mathrm{~m}$ e $3500 \mathrm{~m}$ sendo que nesta última camada o aquecimento é muito pequeno, conforme a figura 4c. Isso explica porque os perfis te temperatura potencial virtual às $17 \mathrm{H}$ são praticamente idênticos nos dois sítios, ou seja, o ar na pastagem está se resfriando na floresta ele está se aquecendo. Por outro lado, quando há resfriamento em ambos os sítios, ele é menor na floresta.

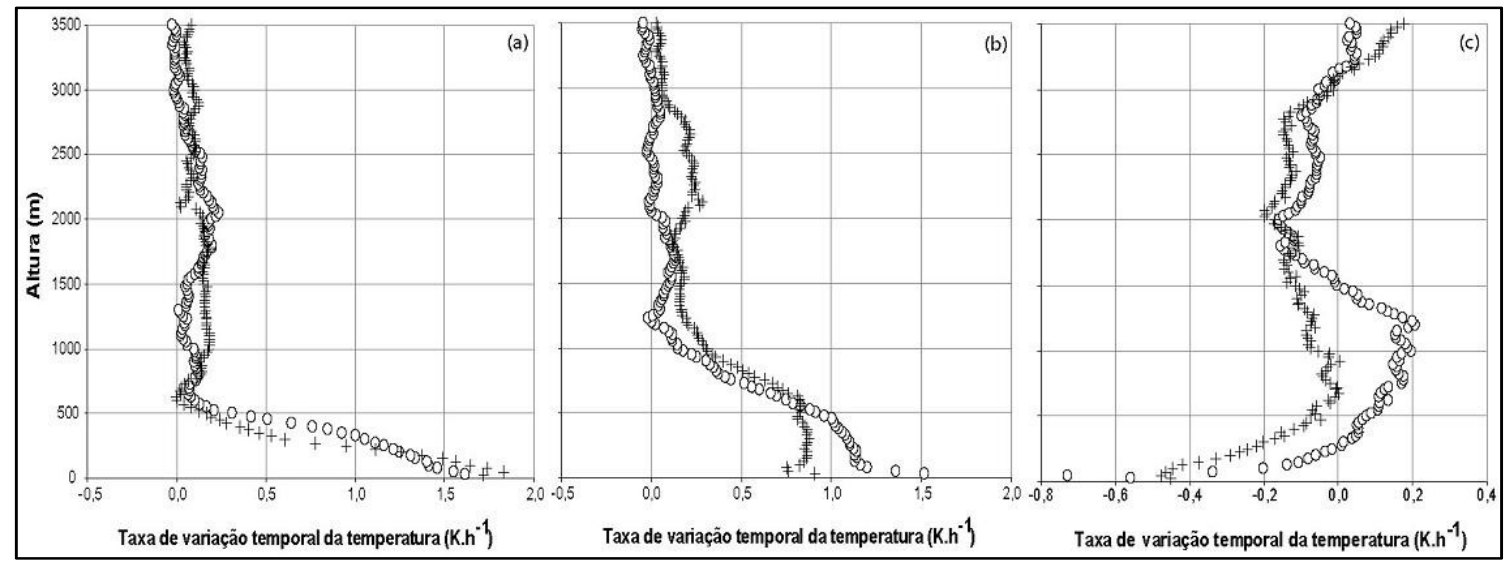

Figura 4: Taxa de evolução temporal da temperatura $(\partial \theta / \partial \mathrm{t})$ na floresta (o) e pastagem $(+)$ nos intervalos de $8 \mathrm{H}-11 \mathrm{H}$ (a), $11 \mathrm{H}-14 \mathrm{H}$ (b) e $14 \mathrm{H}-17 \mathrm{H}$ (c).

Visando verificar se o aquecimento a cima da CLC está ligado com o que ocorre no seu interior, comparamos as taxas médias, no interior da CLC ( 0 a Zi) e acima dela (Zi a 3500m), conforme mostrado na figura 5. Nela verificamos que dentro da CLC o aquecimento é maior na floresta e que acima dela ocorre o inverso. Imaginando que há transferência de calor da CLC para a camada superior (Zi a 3550m) o aquecimento seria maior na floresta onde as taxas de aquecimento são maiores.

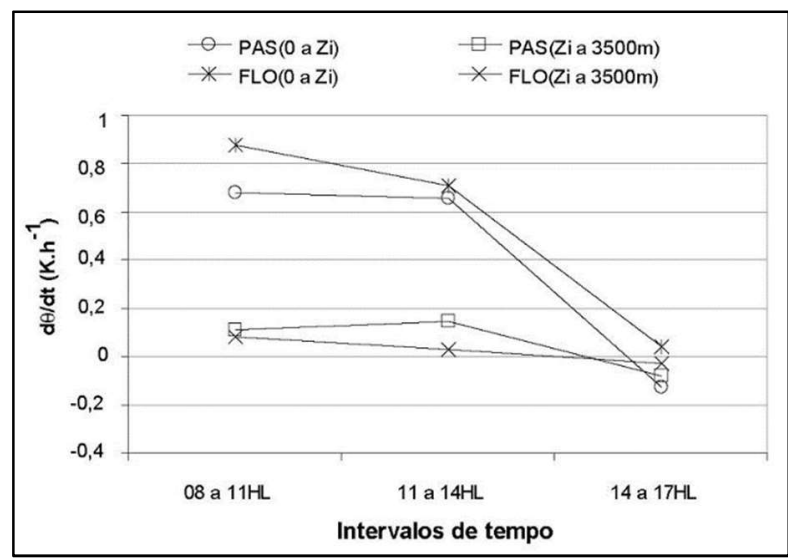

Figura 5: Taxas de aquecimento média no interior da CLC (0 a Zi) e do topo da CLC até 3500m (Zi a 3500m), na floresta e na pastagem.

Uma outra evidência de que isso não ocorre é o fato do aquecimento, acima da CLC, na floresta não apresentar um ciclo semelhante ao observado no interior da CLC. Desta forma, imaginamos que ou a 
transferência de calor na zona de entranhamento ocorre unicamente na pastagem ou o aquecimento acima da CLC se deve unicamente a fenômenos de escala maior. Como a distância entre os dois sítios é de cerca de 80 km a hipótese mais provável é a primeira (transferência apenas na pastagem). Uma outra evidência disso é o resfriamento na CLC da pastagem entre 14 e $17 \mathrm{H}$.

O aparecimento da camada limite estável (CLE) no final da tarde (17H) no perfil médio (Figura 3) foi um fato que de certa forma surpreendeu, pois, no perfil médio da estação chuvosa (ROCHA, 2003) não foi verificado tal fenômeno. Isto não é um fato novo e já havia sido observado na estação seca de 1994 (FISCH et al., 1996 e LYRA et al., 2003) e, em algumas ocasiões, na própria estação chuvosa de 1999 (ROCHA, 2003).

Verificando cada dia separadamente, constatamos o aparecimento da camada estável as $17 \mathrm{H}$ em varias ocasiões conforme pode se verificar no exemplo da Figura 6a. A mesma coisa acontece quando investigamos os perfis da estação seca (SOUSA, 1997). Nele os eventos são mais escassos e, quando ocorre, a camada é bem menos espessa (Figura 6b). Finalmente, o surgimento da camada estável (surgimento precoce da CLN) no final da tarde ocorre normalmente na região, principalmente na estação de transição. Como a referida estação acontece no verão (dias mais longos) o fenômeno em questão certamente está relacionado com a maior quantidade de nebulosidade (tardes mais nubladas).

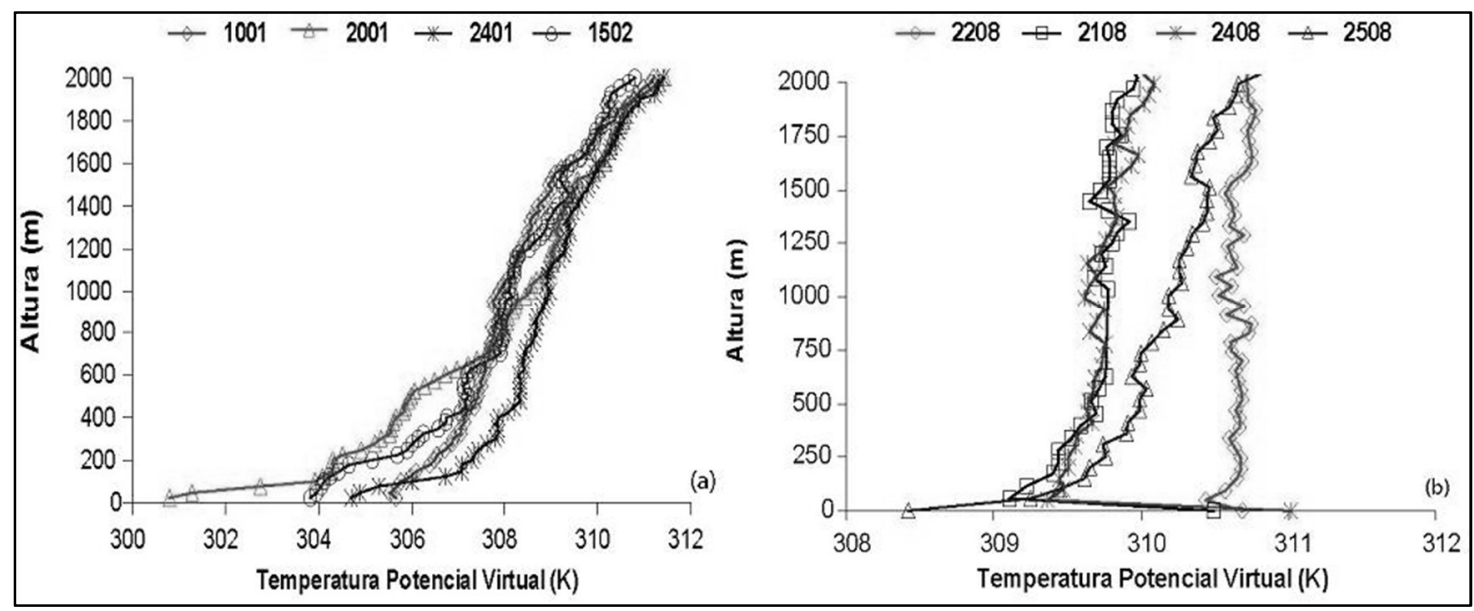

Figura 6: Exemplo de surgimento da camada estável (CE) às 17h na pastagem durante a estação chuvosa de 1999 (a) e estação seca de 1994 (b).

Para averiguar a existência de padrões diferentes no comportamento da CLC em função das estações do ano, será feita a seguir uma comparação entre os nossos resultados (transição seca/chuvosa) com as estações seca de 1994 (SOUSA, 1997) e chuvosa de 1999 (ROCHA, 2003).

Na floresta, consoante ao que será ilustrado pela tabela 2, a evolução temporal da altura da CLC foi maior na estação de transição. Porém, tanto o padrão de crescimento como a altura em si estão mais próximos dos observados na estação chuvosa. A média geral na estação de transição foi de $858 \mathrm{~m}$, enquanto que nas estações seca e chuvosa foi $657 \mathrm{~m}$ e $747 \mathrm{~m}$ respectivamente. No caso da pastagem, como na floresta, os padrões das estações chuvosa e de transição são bastante parecidos, ao passo que o da estação seca se destaca bastante com a CLC atingindo uma altura da ordem de duas vezes a das demais. 
O valor médio para a estação chuvosa é $749 \mathrm{~m}$ enquanto para a estação de transição é de $888 \mathrm{~m}$, já para a estação seca a média foi de $1091 \mathrm{~m}$. Com relação a temperatura potencial (TP) e o gradiente de $\theta_{V}$ (GR $\theta_{\mathrm{v}}$ ) tanto na floresta quanto na pastagem foram bastante parecidos nos três períodos. Na floresta assim como na pastagem a TP foi maior na estação de transição $\left(305,3 \mathrm{~K}\right.$ e $306,2 \mathrm{~K}$, respectivamente) já o GR $\theta_{V}$ foi negativo nos períodos seco e chuvoso e nulo no de transição para os dois sítios. A velocidade do vento na pastagem foi maior no período chuvoso $\left(3.1 \mathrm{~m} . \mathrm{s}^{-1}\right)$ e na floresta no seco $\left(2,7 \mathrm{~m} . \mathrm{s}^{-1}\right)$. A umidade especifica foi bastante similar nos períodos chuvoso e de transição na pastagem enquanto que na floresta ocorreu o mesmo sendo que no período seco ela foi maior que na pastagem nesse mesmo período.

Tabela 2: Comparação do comportamento da CLC na floresta e na pastagem durante os períodos seco, chuvoso e de transição. Fonte: Sousa (1997); Rocha (2003).

\begin{tabular}{|c|c|c|c|c|c|c|c|c|c|}
\hline & & \multicolumn{4}{|c|}{ Pa stagem } & \multicolumn{4}{|c|}{ Floresta } \\
\hline & & Seco* & Churoso** & Transição & (Flo - Pas) & Seco* & Chuvoso** & Transição & (Flo - Pas) \\
\hline \multirow{2}{*}{$\mathrm{Zi}_{\mathrm{m}}$} & Média & 1091 & 749 & 888 & 342 & 657 & 747 & 858 & -89 \\
\hline & Desv. Pad. & 194 & 224 & 341 & -30 & 130 & 227 & 285 & -97 \\
\hline \multirow{2}{*}{$\theta_{\mathrm{V}}$} & Média & 304,4 & 301,8 & 306,2 & 2,7 & 301,7 & 300,8 & 305,3 & 0,9 \\
\hline & Desv. Pad. & 1,3 & 1,3 & 1,4 & 0,0 & 1,0 & 1,4 & 1,0 & $-0,3$ \\
\hline \multirow{2}{*}{ GR $\theta_{\mathrm{V}}$} & Média & $-0,7$ & $-0,3$ & 0,0 & $-0,4$ & $-1,8$ & $-3,0$ & 0,0 & 1,2 \\
\hline & Desv. Pad. & 2,6 & 2,0 & 0,0 & 0,6 & 4,5 & 3,8 & 0,0 & 0,7 \\
\hline ff & Média & 2,6 & 3,1 & 1,9 & $-0,6$ & 2,7 & 2,4 & 1,9 & 0,3 \\
\hline \multirow{2}{*}{$q$} & Média & 9,9 & 16,4 & 14,5 & $-6,6$ & 12,9 & 15,7 & 14,6 & $-2,8$ \\
\hline & Desv. Pad. & 1,3 & 1,0 & 2,4 & 0,3 & 0,8 & 0,9 & 1,0 & $-0,1$ \\
\hline
\end{tabular}

\section{CONCLUSÕES}

Na transição da estação seca para a chuvosa (LBA 2002), a evolução da CLC sobre a floresta e sobre a pastagem foi praticamente idêntica. No interior da CLC os padrões de evolução dos parâmetros médios e das taxas de variação temporal nos dois sítios foram, na sua maioria, semelhantes. Apesar disso, algumas diferenças foram constatadas, por exemplo, no ambiente modificado (pastagem) a CLC apresentou temperatura ligeiramente superior $(306,15 \mathrm{~K}$ contra $305,30 \mathrm{~K})$ e gradiente de temperatura um pouco menor $\left(-0,0035 \mathrm{~K} \cdot \mathrm{m}^{-1}\right.$ contra $\left.-0,0015 \mathrm{~K} \cdot \mathrm{m}^{-1}\right)$. A taxa de aquecimento no seu interior foi um pouco menor $\left(0,4 \mathrm{~K} \cdot \mathrm{h}^{-1}\right.$ contra $\left.0,54 \mathrm{~K} \cdot \mathrm{h}^{-1}\right)$. A umidade foi praticamente igual $\left(14,51 \mathrm{~g} \cdot \mathrm{kg}^{-1}\right.$ contra $\left.14,63 \mathrm{~g} \cdot \mathrm{kg}^{-1}\right)$ e o gradiente de umidade maior $\left(-0,006 \mathrm{~g} \cdot \mathrm{kg}^{-1} \cdot \mathrm{m}^{-1}\right.$ contra $\left.-0,008 \mathrm{~g} \cdot \mathrm{kg}^{-1} \cdot \mathrm{m}^{-1}\right)$. Aparentemente, há uma ligação mais estreita entre a CLC $\mathrm{e}$ a atmosfera livre na pastagem. Verificou-se que o surgimento com mais freqüência e intensidade da camada estável (CLN) no final da tarde é um fenômeno característico da estação.

\section{REFERÊNCIAS}

CIAMPI, B. L.; SILVA, A. E.; DA SILVA, D. A. F.; SILVA, M. R. G.; LEITE, C. C.; LYRA, R. F. F.; ROCHA, C. H. E. D.. Evolução da Camada Limite Atmosférica no Oeste da Amazônia:
Comparação entre as Estações Seca e Chuvosa. CONGRESSO BRASILEIRO DE METEOROLOGIA, 12. Anais. Foz do Iguaçu, 2002. 
COHEN, J. C. P.; COSTA, W.; DIAS, M. A. F. S.. Características Médias das Linhas de Instabilidade Durante o período Chuvoso do WET AMC/LBA. In: CONGRESSO BRASILEIRO DE METEOROLOGIA, 10. Anais. Rio de Janeiro, 2000.

CULF, A. D.; FISCH, G.; NOBRE, C. A.. Modelling Convective Boundary Layer Growth in Rondonia. In: Deforestation and Climate. Chichester: John Wiley \& Sons, 1996.

FINNIGAN, J. J.; KAIMAL, J. C.. Atmospheric boundary layer flows their structure and measurement. New York: Oxford University Press, 1994.

FISCH, G.; MARENGO, J. A.; NOBRE, C. A.. Clima da Amazônia. Revista Climanálise. Recife: 1996.

LYRA, R. F. F.; ROCHA, C. H. E. D.. Acompanhamento das Condições Meteorológicas Durante o LBA/TRMM, 1999. CONGRESSO BRASILEIRO DE AGROMETEOROLOGIA, 13. Anais. Santa Maria, 2003.

MOLION, L. C. B.. Global Climate Impacts of Amazonia Deforestation. Revista Geofisica, v.42, 1995.

ROCHA, C. H. E. D.. Termodinâmica da Camada Limite Atmosférica durante a Estação Chuvosa no Oeste da Amazônia: LBA/TRMM. Dissertação (Mestrado) Universidade Federal de Alagoas, Maceió, 2003.

SILVA, M. R. G.; FISCH, G.; LYRA, R. F. F.; MOLION, L. C. B.; NOBRE, C. A.. Some Aspects of the Atmospheric Boundary Layer Over Western Amazonian: Dry Season 1994. Revista Brasileira de Meteorologia, v.18, n.1, 2003.

SILVA, M. R. G.; FISCH, G.; LYRA, R. F. F.; ROCHA, C. H. E. D.. Camada Limite no Oeste da Amazônia (Rondônia):

Comparação entre as Estações Seca/1994 e Chuvosa/1999. WORKSHOP BRASILEIRO DE MICROMETEOROLOGIA, 3.

Anais. Santa Maria, 2003.

SOUSA, S. S.. A Substituição da Floresta Amazônica por Pastagem e sua Repercurssão ao Nível da Termodinâmica da Camada Limite Atmosférica: Projeto RBLE. Dissertação (Mestrado) - Universidade Federal da Paraiba, Campina Grande, 1997.

STULL, R. B.. Introduction to Boundary Layer Meteorology. London: Kluwer Academic Publishers, 1988. 